\title{
AOR
}

Selected Papers of \#AolR2020:

The $21^{\text {st }}$ Annual Conference of the Association of Internet Researchers

Virtual Event / 27-31 October 2020

\section{PERCEPTIONS OF ALGORITHMIC PROFILING ON FACEBOOK AND THEIR SOCIAL IMPLICATIONS}

\author{
Aurelia Tamò Larrieux \\ University of Zurich, Switzerland \\ Eduard Fosch Villaronga \\ Leiden University, Netherlands \\ Shruthi Velidi \\ Independent Scholar, USA \\ Salome Viljoen \\ New York University, Cornell Tech, USA \\ Christoph Lutz \\ BI Norwegian Business School, Norway \\ Moritz Büchi \\ University of Zurich, Switzerland
}

\section{Background and Research Questions}

With every digital interaction, individuals are increasingly subject to algorithmic profiling, for example via targeted advertising on social media. Large Internet firms, such as Facebook and Google/Alphabet, as well as third-party data brokers collect and combine detailed personal data to create sophisticated profiles (Bach et al., 2019) used for predictive purposes. We understand profiling here as the systematic and purposeful recording and classification of data related to individuals (Büchi et al., 2019). Research has started to look into people's perception and engagement of algorithms (Bucher,

Suggested Citation (APA): Tamò Larrieux, A., Fosch Villaronga, E., Velidi, S., Viljoen, S., Lutz, C., \& Büchi, M., (2020, October). Perceptions of Algorithmic Profiling on Facebook and Their Social Implications. Paper presented at AolR 2020: The 21 ${ }^{\text {th }}$ Annual Conference of the Association of Internet Researchers. Virtual Event: AolR. Retrieved from http://spir.aoir.org. 
2017; Duffy et al., 2017; Eslami et al., 2015; Klawitter \& Hargittai, 2018). Notably, this research has shown that many users are unaware of the existence of algorithms, for example those which curate news feeds (Eslami et al., 2015), and that a majority feels uncomfortable with algorithmic profiling on Facebook (Hiltin \& Rainie, 2019). In our research, we investigate perceptions of algorithmic profiling on Facebook by addressing the following questions: What user narratives of profiling on Facebook exist? What reactions do users have when confronted with Facebook's inferred profiles? What are the social implications of user perceptions of profiling?

\section{Research Design}

Relying on Prolific for participant recruitment and Qualtrics for the questionnaire design, we created an online survey in November 2019. We limited participation to active Facebook users in the US and obtained 292 valid responses. The survey included questions on demographics, privacy concerns, privacy-protection behavior, social media and Internet use, and an in-depth section on respondents' perception of profiling, based on Facebook's "Your interests" and "Your categories" sections in the Ad Preferences menu (Hiltin \& Rainie, 2019). We used five open text boxes to elicit the narratives, imaginaries, and reactions to Facebook's algorithmic profiling. The data analysis is ongoing and for this contribution, we present the findings of a thematic analysis of the textual data as well as descriptive statistics for the closed questions.

\section{Results and Discussion}

To explore user narratives of profiling, we asked the following questions: How do you think Facebook determines which ads to display to you? and What kind of data do you think Facebook has about you? We analyzed the second question in more depth and extracted four key perceptions: a) uncertainty: respondents do not know what kind of data Facebook has about them and admit their lack of knowledge; b) naiveté: respondents think that Facebook only has the information they explicitly shared (no inferences); c) realism: respondents are aware that Facebook has information that goes beyond what is immediately visible; d) fatalism: respondents think that Facebook knows everything. Theme c) was most prevalent but a fair proportion of respondents fell into the b) and d) categories. Figure 1 shows a word cloud visualization for this question. The prominent role of "everything" and "know" implies narratives of Facebook as powerful and intrusive, as evidenced by individual quotes.

This is partly contrasted by the reaction to the actual displays of profiling. Using closed questions, we found that the perceived accuracy of "My Interests" was only moderate $(3.30 / 5)$ and the same is true for "My Categories" (3.25/5). However, "My Interests" and "My Categories" differed in the level of perceived detail, measured by the question: Is the number of interests/categories higher, lower, or about what you expected? (separately asked for interests and categories after inspection of "My Interests" and "My Categories"). The number of interests listed tended to be higher than expected, whereas the number of categories listed tended to be lower than expected. The openended reactions to seeing "My Interests" and "My Categories" varied broadly, from not 
surprised at all to shocked. Many respondents were surprised at how imprecise or even wrong some of the inferred interests and categories were. These findings paint a more differentiated picture than the initial narratives.

These findings have implications for research on algorithms from a user-centered perspective (Bucher, 2017; Duffy et al., 2017; Eslami et al., 2015; Klawitter \& Hargittai, 2018). Particularly, they point to aspects of social exclusion and social justice, as users might differentially benefit or be disadvantaged from their digital traces (Micheli et al., 2018). If users have overly pessimistic imaginaries of algorithmic profiling, they might be excluded from opportunities the Internet and social media offer (Schradie, 2013). By contrast, if they have overly optimistic imaginaries of algorithmic profiling, they might fall prey to online fraud or abuse more easily (Madden et al., 2017). Thus, the findings connect to the debate about algorithmic literacy. Particularly, knowledge about profiling and algorithmic literacy could be associated with chilling effects that affect those at the margins most strongly, potentially leading to a society with less space for nonconformity and alternative lifestyles (Büchi et al., 2019). In a follow-up study to the research presented here, we aim to connect perceptions of profiling to chilling effects.

Figure 1. Users' perceptions of Facebook's data about them

What kind of data do you think Facebook has about you?

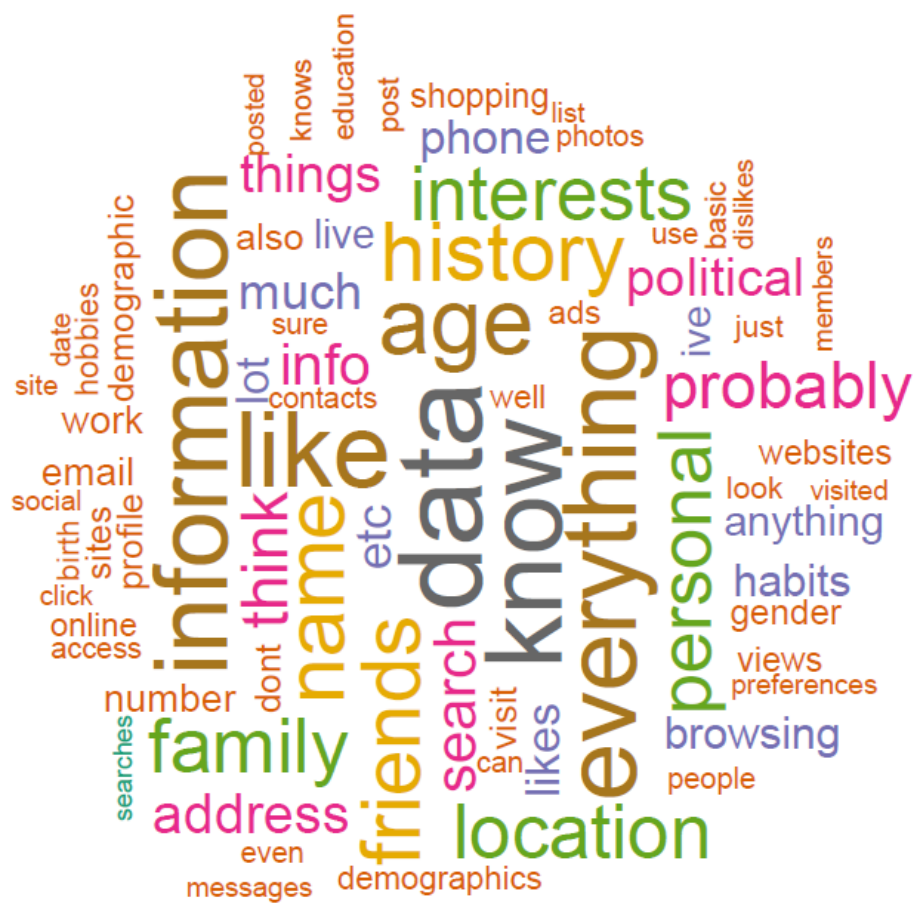




\section{References}

Bach, R. L., Kern, C., Amaya, A., Keusch, F., Kreuter, F., Hecht, J., \& Heinemann, J. (2019). Predicting voting behavior using digital trace data. Social Science Computer Review, online first. https://doi.org/10.1177/0894439319882896

Bucher, T. (2017). The algorithmic imaginary: exploring the ordinary affects of Facebook algorithms. Information, Communication \& Society, 20(1), 30-44.

Büchi, M., Fosch-Villaronga, E., Lutz, C., Tamò-Larrieux, A., Velidi, S., \& Viljoen, S. (2019). The chilling effects of algorithmic profiling: Mapping the issues. Computer Law \& Security Review, online first. https://doi.org/10.1016/j.clsr.2019.105367

Duffy, B. E., Pruchniewska, U., \& Scolere, L. (2017). Platform-specific self-branding: Imagined affordances of the social media ecology. In Proceedings of the 8th International Conference on Social Media \& Society (pp. 1-9). ACM.

Eslami, M., Rickman, A., Vaccaro, K., Aleyasen, A., Vuong, A., Karahalios, K., ... \& Sandvig, C. (2015). I always assumed that I wasn't really that close to [her]: Reasoning about Invisible algorithms in news feeds. In CHl'15: Proceedings of the 33rd Annual ACM Conference on Human Factors in Computing Systems (pp. 153-162). ACM.

Hiltin, P., \& Rainie, L. (2019). Facebook algorithms and personal data. Pew Research Center: Internet \& Technology Report, 16 January 2019. https://www.pewinternet.org/2019/01/16/facebook-algorithms-and-personal-data/

Klawitter, E., \& Hargittai, E. (2018). "It's like learning a whole other language": The role of algorithmic skills in the curation of creative goods. International Journal of Communication, 12, 3490-3510.

Madden, M., Gilman, M., Levy, K., \& Marwick, A. (2017). Privacy, poverty, and big data: A matrix of vulnerabilities for poor Americans. Washington University Law Review, 95, 53-126.

Micheli, M., Lutz, C., \& Büchi, M. (2018). Digital footprints: an emerging dimension of digital inequality. Journal of Information, Communication and Ethics in Society, 16(3), 242-251.

Schradie, J. (2013). Big data not big enough? How the digital divide leaves people out. MediaShift, 31 July 2013. http://mediashift.org/2013/07/big-data-not-big-enough-howdigital-divide-leaves-people-out/ 